The Beaufort Gyre Observing System 2004:

Mooring Recovery and Deployment Operations in Pack Ice

by

J. Kemp, K. Newhall, W. Ostrom, R. Krishfield, and A. Proshutinsky

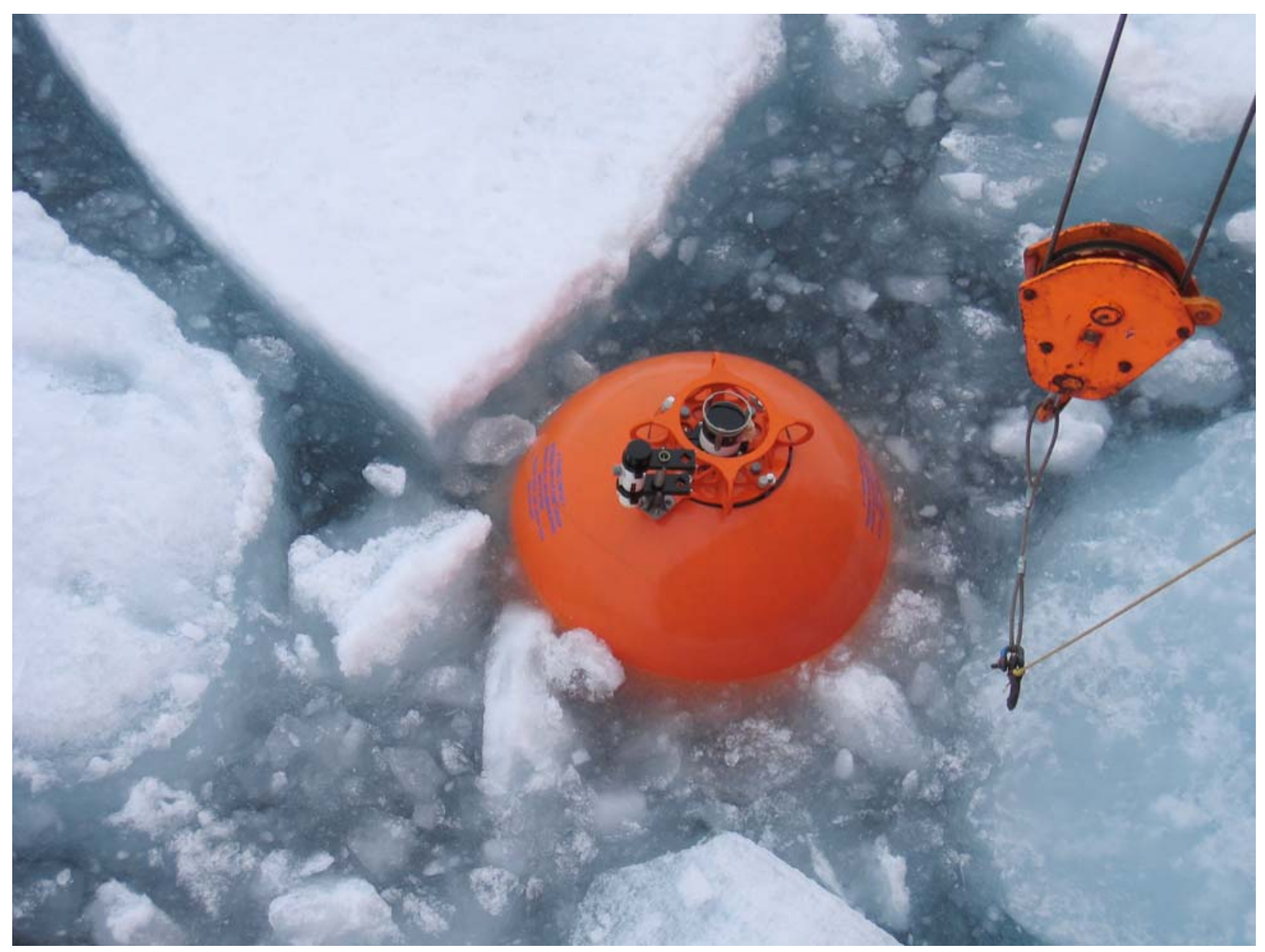

Woods Hole Oceanographic Institution

Technical Report WHOI-2005-05

http://www.whoi.edu/beaufortgyre 


\begin{abstract}
Situated beneath the Arctic perennial ice pack, the principal components of the Beaufort Gyre Observing System are three deep-ocean bottom-tethered moorings with CTD and velocity profilers, upward looking sonars for ice draft measurements, and bottom pressure recorders. A major goal of this project is to investigate basin-scale mechanisms regulating freshwater and heat content in the Arctic Ocean and particularly in the Beaufort Gyre throughout several complete annual cycles. The methods of recovering and re-deploying the $3800 \mathrm{~m}$ long instrumented moorings from the Canadian Coast Guard Icebreaker Louis S. St. Laurent in August 2004 are described.

In ice-covered regions, deployments must be conducted anchor-first, so heavier wire rope and hardware must be incorporated into the mooring design. Backup buoyancy at the bottom of the mooring is advised for backup recovery should intermediate lengths of the mooring system get tangled under ice floes during recovery. An accurate acoustic survey to determine the exact location of the mooring, adequate ice conditions, and skilled ship maneuvering are all essential requirements for a successful mooring recovery. Windlass (or capstan) procedures could be used for the recovery, but a traction winch arrangement is recommended.
\end{abstract}




\section{Project Overview}

The Beaufort Gyre has been characterized in the past as the region of "relative inaccessibility" in the Arctic Ocean because of the difficulty of accessing the area by icebreaker due to heavy ice conditions and by airplane due to its remoteness from the mainland. As a result, the area is one of the most poorly sampled regions in the Arctic Ocean. In 2002, the National Science Foundation (NSF) Office of Polar Programs recognized the great importance of the Beaufort Gyre in the fresh water balance of the Arctic Ocean and funded the "Beaufort Gyre Freshwater Experiment (BGFE): Study of fresh water accumulation and release mechanism and a role of fresh water in Arctic climate variability" (Principal Investigator, Andrey Proshutinsky). The major goal of this project was to investigate basin-scale mechanisms regulating freshwater content in the Arctic Ocean and particularly in the Beaufort Gyre throughout a complete annual cycle. As part of the field experiment for this project, three bottom-tethered moorings were deployed with CTD and velocity profilers, upward looking sonars for ice draft measurements, and bottom pressure recorders, and four expendable surface buoys with CTDs during a Joint Western Arctic Climate Study (JWACS) cruise on the Canadian Coast Guard Icebreaker Louis S. St. Laurent (LSL) in August 2003 (Ostrom et al., 2004).

However, given the importance of this region for Arctic climate studies, it was desired to investigate interannual and longer variability, so that it was necessary to continue acquiring the same data for several years, although the observational program supported by NSF would end with recovery of the moorings in 2004. In 2004, WHOI's Ocean and Climate Change Institute provided the support to redeploy the three moorings in order to continue monitoring freshwater and heat content in this climatically sensitive region of the Arctic Ocean, thus establishing the Beaufort Gyre Observing System (BGOS).

In August 2004, the sites were revisited, the moorings were recovered, data were retrieved from the instruments, the hardware and sensors were refurbished, and the systems were redeployed at the same locations again from the LSL during a JWACS cruise (Figure 1). In addition, a prototype Ice-Tethered Profiler (ITP) buoy was deployed in combination with an Ice Mass Balance (IMB) buoy. The times and locations of the 
recovery and deployment operations are given in Table 1. More information on the BGFE/BGOS project, including the scientific motivation, publications, descriptions of methods (instruments and modelling), field operations (including dispatches from each of the cruises), historical and acquired data, and a "History of Arctic Exploration and Scientific Discovery" are available at http://www.whoi.edu/beaufortgyre.

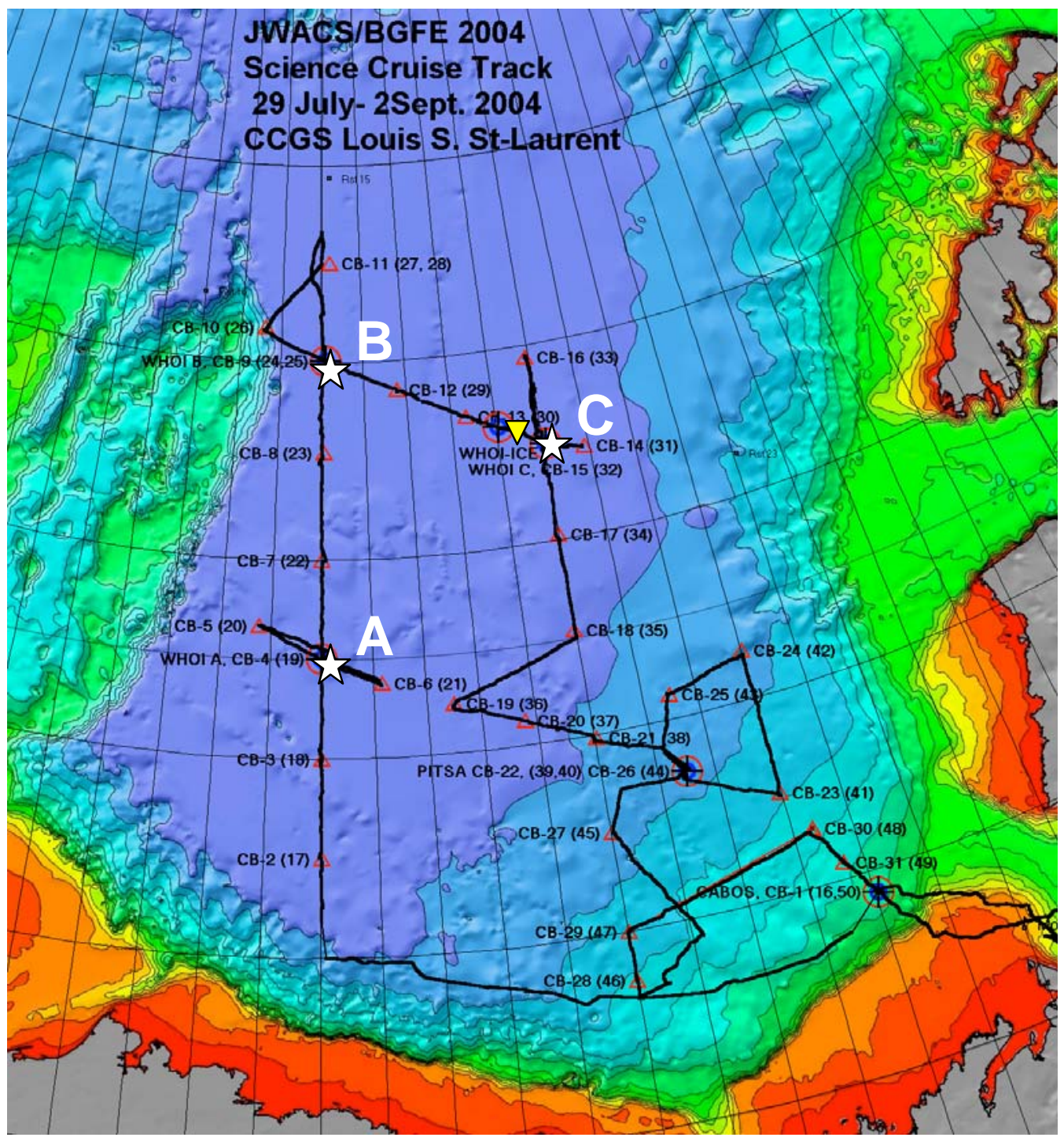

Figure 1: JWACS 2004 cruise track (Figure by Sarah Zimmermann), with BGOS mooring locations (stars), and ITP/IMB deployment location (inverted triangle). 
In 2004, NSF granted a 5-year proposal “The Beaufort Gyre System: Flywheel of the Arctic Climate?" so that all the moorings that are recovered in 2005 with support of the WHOI Ocean and Climate Change Institute, will be maintained until 2008 with NSF support and investigation of the Beaufort Gyre system will continue.

Table 1: Summary of BGFE/BGOS 2004 field operations.

\begin{tabular}{|c|c|c|c|c|c|}
\hline $\begin{array}{l}\text { Mooring } \\
\text { Designation }\end{array}$ & $\begin{array}{c}\text { Water } \\
\text { Depth (m) }\end{array}$ & $\begin{array}{l}2003 \\
\text { Location }\end{array}$ & $\begin{array}{c}2004 \\
\text { Recovery }\end{array}$ & $\begin{array}{c}2004 \\
\text { Deployment }\end{array}$ & $\begin{array}{c}2004 \\
\text { Location }\end{array}$ \\
\hline BGFE-A & 3824 & $\begin{array}{c}75^{\circ} 00.39^{\prime} \mathrm{N} \\
149^{\circ} 58.752^{\prime} \mathrm{W}\end{array}$ & $\begin{array}{c}\text { 10-Aug } \\
\text { 14:34 UTC }\end{array}$ & $\begin{array}{c}\text { 12-Aug } \\
\text { 19:58 UTC }\end{array}$ & $\begin{array}{l}75^{\circ} 00.242^{\prime} \mathrm{N} \\
149^{\circ} 57.742 \mathrm{~W}\end{array}$ \\
\hline BGFE-B & 3821 & $\begin{array}{l}78^{\circ} 01.491^{\prime} \mathrm{N} \\
149^{\circ} 49.378^{\prime} \mathrm{W}\end{array}$ & $\begin{array}{c}\text { 15-Aug } \\
\text { 13:23 UTC }\end{array}$ & $\begin{array}{c}\text { 17-Aug } \\
\text { 17:59 UTC }\end{array}$ & $\begin{array}{l}78^{\circ} 00.9677^{\prime} \mathrm{N} \\
149^{\circ} 51.544^{\prime} \mathrm{W}\end{array}$ \\
\hline BGFE-C & 3722 & $\begin{array}{l}76^{\circ} 59.254^{\prime} \mathrm{N} \\
139^{\circ} 54.229^{\prime} \mathrm{W}\end{array}$ & $\begin{array}{l}\text { 20-Aug } \\
\text { 18:57 UTC }\end{array}$ & $\begin{array}{c}\text { 22-Aug } \\
\text { 19:31 UTC }\end{array}$ & $\begin{array}{l}76^{\circ} 59.4577^{\prime} \mathrm{N} \\
139^{\circ} 58.407^{\prime} \mathrm{W}\end{array}$ \\
\hline \multicolumn{4}{|c|}{$\begin{array}{l}\text { ITP \& IMB } \\
\text { (buoy location is ship's position } \sim 500 \text { m from site) }\end{array}$} & $\begin{array}{c}\text { 19-Aug } \\
\text { 15:00 UTC }\end{array}$ & $\begin{array}{c}77^{\circ} 10.4^{\prime} \mathrm{N} \\
141^{\circ} 13.0^{\prime} \mathrm{W}\end{array}$ \\
\hline
\end{tabular}

\section{Mooring Design}

The bottom-tethered moorings which were deployed in 2003 are described thoroughly in Ostrom et al. (2003). Briefly, each mooring consists of a top sphere providing $2500 \mathrm{lb}$ of buoyancy and housing an Upward Looking Sonar (ULS) and Benthos transponder. The length of each mooring was individually adjusted so that the top sphere would be located at $45 \mathrm{~m}$, however only one of the three moorings actually ended up close to the correct depth while the other two ended up deeper than intended due to uncertainties in the bottom depth and incorrect wire lengths. The ULS acquires ice draft data, while the transponder is used for remotely determining the location of the mooring by performing an acoustic survey. 


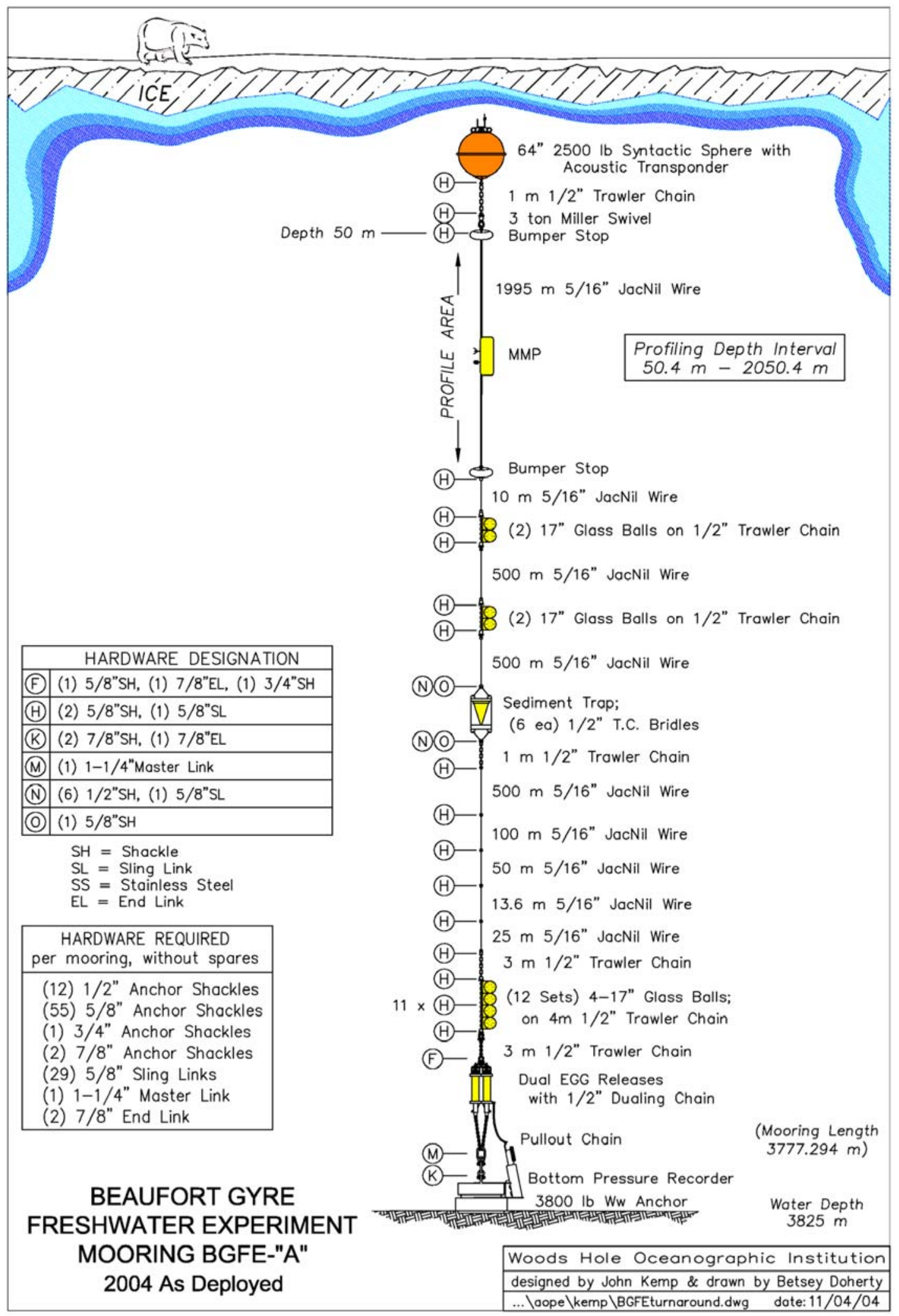

Figure 2: BGOS mooring schematic as deployed in 2004. 
Below the top sphere and chain bridle, a $2000 \mathrm{~m}$ segment of wire rope supports a McLane Moored Profiler (MMP), which acquires seawater temperature, salinity and velocity profiles approximately twice every two days between about 50 and $2000 \mathrm{~m}$. Where the upper sphere was deeper than intended, the upper limit of the MMP is also deeper. Below the MMP, various wire rope segments and glass floats were distributed to fill in the mooring length, reduce tension on the wire during deployment, and provide backup buoyancy for recovery.

On one mooring (A), a McLane Research sediment trap was installed at $3000 \mathrm{~m}$ depth for a biogeochemical particle flux study. At the bottom of each mooring is a 3800 $\mathrm{lb}$ anchor, with mount for a Bottom Pressure Recorder (BPR) to measure the pressure of the entire water column. The BPR is attached to a set of dual releases which are suspended above the anchor. Triggering one of the two releases with an acoustic pulse causes the entire system (except anchor) to float to the surface where it can be recovered.

On all the moorings, the glass flotation spheres were redistributed differently along the mooring in 2004 compared to 2003, in order to reduce tangling of the wire on recovery. A schematic of the BGFE mooring design as redeployed in 2004 is presented in Figure 1.

\section{Methods}

The method of deploying and recovering bottom-tethered moored instruments in Arctic ice-covered waters from air supported landings and using divers for recovery was described by Aagaard et al. (1978). Before icebreaker vessels were able to regularly penetrate the perennial ice pack, these air supported operations (also employed by Institute of Ocean Sciences (IOS), Canada) provided the only means to regularly revisit moored sites, and are still utilized today for annual maintenance of North Pole Environmental Observatory systems (http://psc.apl.washington.edu/northpole). In this technical report, we describe the methods of recovering and re-deploying instrumented deep-ocean bottom-tethered moorings within the Arctic perennial ice pack from icebreakers without diver assistance. 
Table 2: Table of weights and tensions for BGOS mooring A as deployed in 2004.

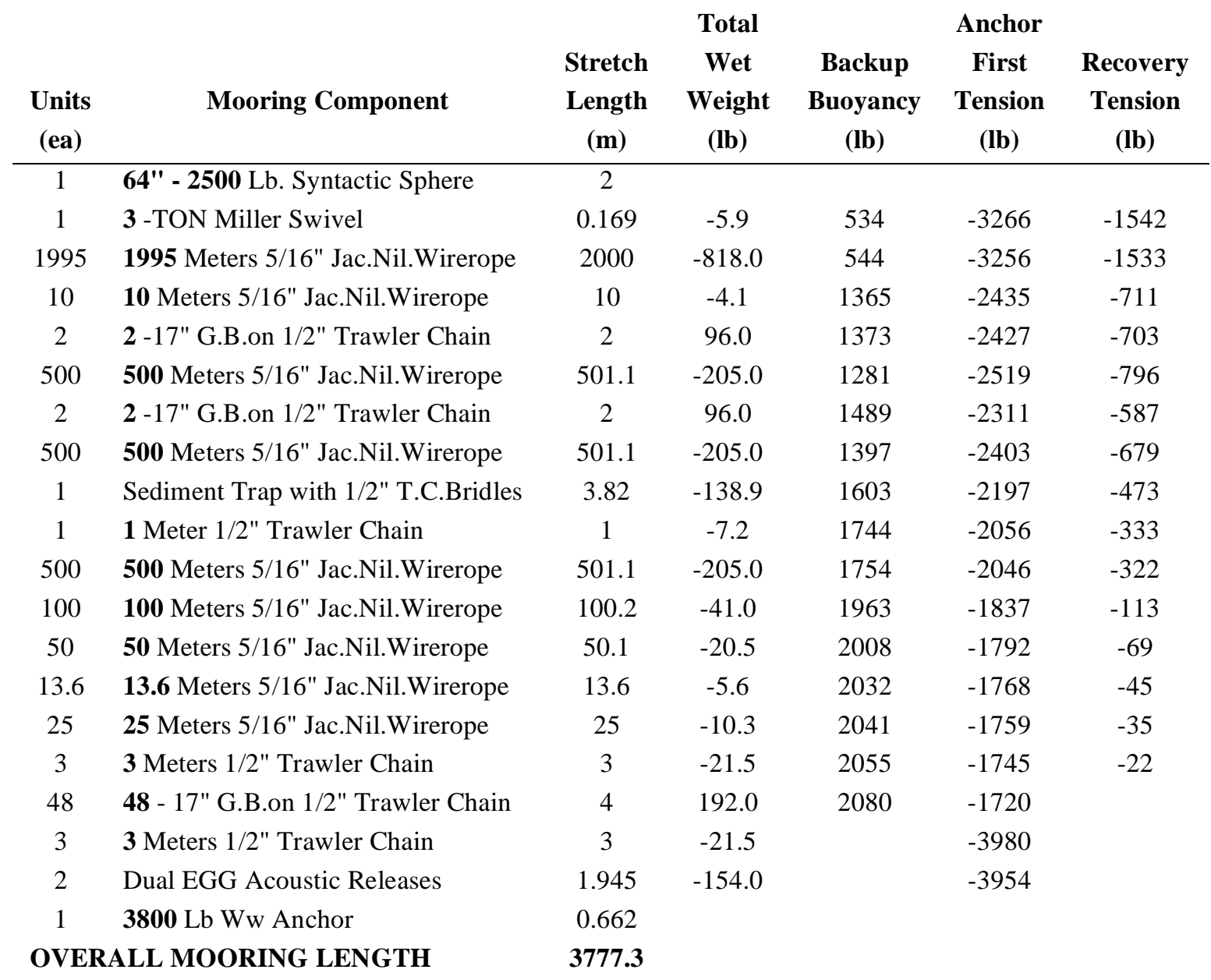

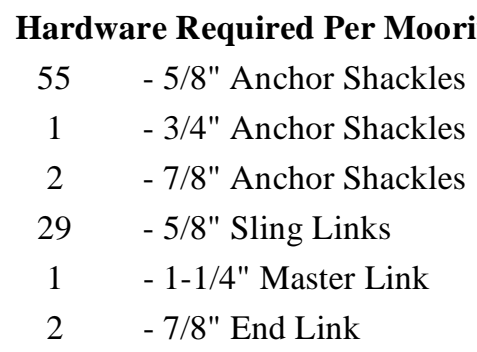

In the Arctic ice pack, it is not normally feasible to deploy bottom-tethered moorings in the traditional manner of spooling out the entire mooring on the surface and deploying the anchor last. Consequently, the anchor must be deployed first, which increases the working tension during deployment. As a result, the BGOS moorings are 
designed with: 1) heavier gauge wire rope (5/16") for increased strength, and 2) backup flotation at the bottom to allow for the entire mooring to be recovered if the mooring parts during deployment (or anytime prior to recovery). The backup buoyancy also allows the mooring to be recovered from the bottom end if the upper mooring becomes tangled in ice floes during recovery.

Table 2 lists the design weights, lengths and buoyancies of mooring A as deployed in 2004, and estimated tensions during deployment and recovery. Note that the minimum backup buoyancy at any time during deployment is always greater than $500 \mathrm{lb}$. Static tension varies from as much as $4000 \mathrm{lb}$ to as little as $1700 \mathrm{lb}$ during the deployment as each item of equipment and flotation are attached. Tension during recovery is always less than $1600 \mathrm{lb}$.

\section{Recovery Platform - CCGS Louis S. St. Laurent}

Unlike most mooring operations conducted on UNOLS vessels where the mooring deployment and recoveries are performed from the stern of the vessel, mooring operations on the LSL are conducted from the foredeck of the ship. The work area is equipped with a starboard side A-frame and two stiff boom cranes located on either side of the foredeck, each capable of lifting heavy gear out of the water. The deployment cruise on the LSL in 2003 utilized the ships windlass to deploy the BGOS moorings, but this technique proved to be rather slow and labor intensive, and would be more so during recovery operations. Consequently, a special traction mooring winch system (manufactured by the Lebus company in England) and custom fairlead plate were installed on the ship for use in conjunction with the ship's cranes and A-frame in the recovery and re-deployment of the moorings in 2004 (Figure 3).

\section{Traction Winch}

The Lebus traction winch system consists of three primary components: the double barreled capstan, spooler winch and power pack. The function of the winch system allows mooring wires and ropes to be deployed and recovered utilizing a double 
headed capstan acting as a traction winch in conjunction with a tension spooling winch that provides constant back tension on the mooring wire and supports individual wire and rope mooring segments reels.

The double barreled capstan is the load bearing or hauling segment of the winch system (high tension component), and the spooler winch is the mooring wire and rope delivery system (low tension component). In haul mode, this system operates by the capstan winch pulling the mooring wire (with constant tension) from the spooler winch.

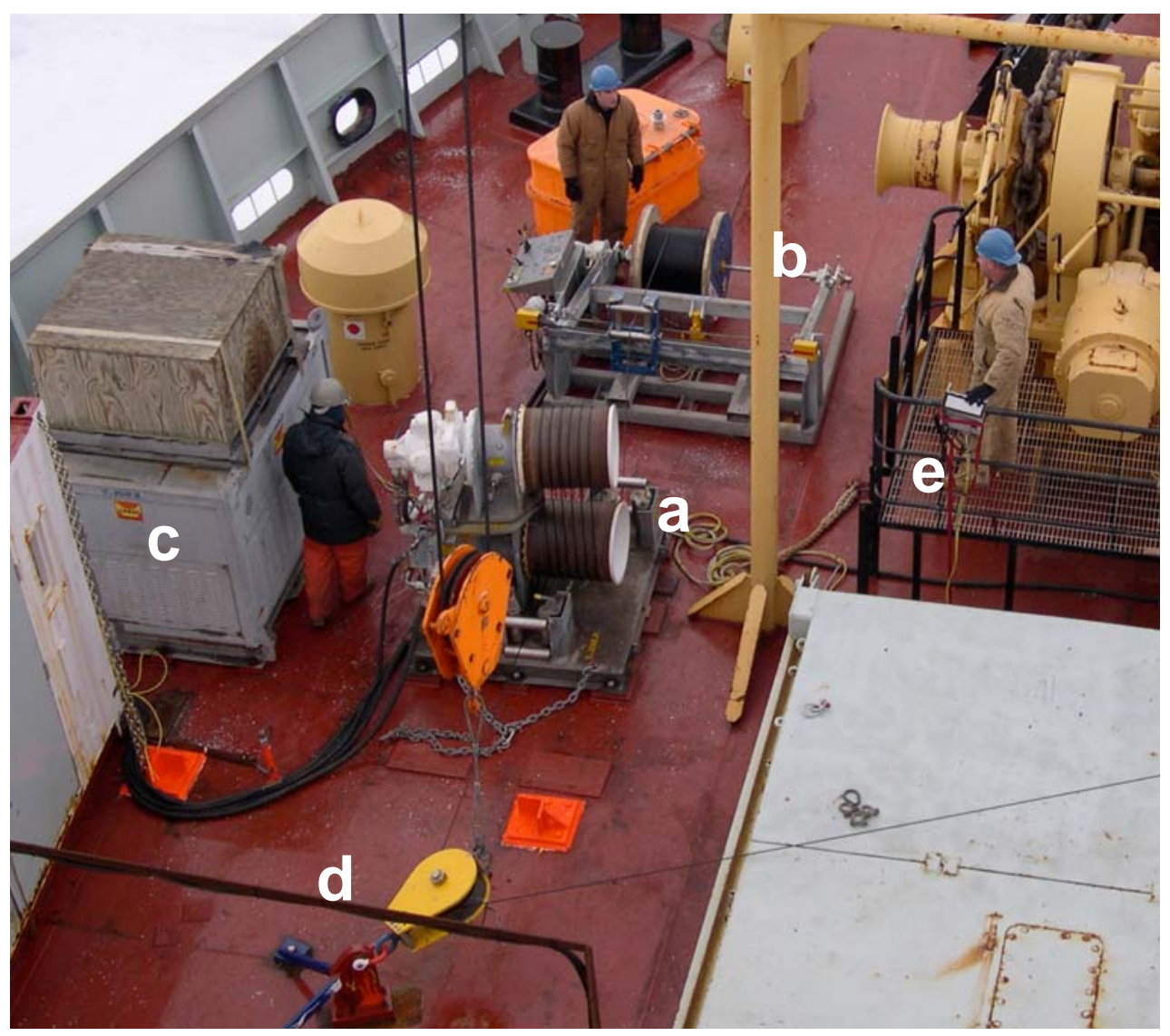

Figure 3. The Lebus traction winch system installed on the fore deck of the LSL: a) double barreled capstan, b) spooler winch, c) power pack, d) fairlead plate and block, e) remote control box.

The capstan winch has two capstan barrels positioned horizontally one over the other. There are two fair lead gates located at the front and rear of the winch through 
which the mooring wire enters and exits. The free end of the mooring wire is guided through the front fairlead gate (low tension side), wound around the two capstan barrels with typically 5 to 6 wraps, and passed out through the rear fair lead gate (high tension side). The axial ordination of the upper barrel is important in maintaining adequate separation between the wire wraps. The separation between each wrap can be adjusted by activating a manual hydraulic control pump that pivots the upper capstan barrel horizontally, causing the wire wraps to migrate towards the desired inner or outer edge of the barrels. The capstan winch is operated from a remote control box. This control box is fitted with an emergency stop button and a toggle control that allows the capstan barrels to operate at infinite speeds. The winch's operating capacity is $7000 \mathrm{lb}$ at $30 \mathrm{fpm}$.

The spooler winch is a hydraulically powered reel stand that is controlled separately from the capstan winch. This winch is designed to support wooden wire and rope storage reels and to provide a haul in line tension up to $250 \mathrm{lb}$. The spooler winch should nominally maintain between 125 to $150 \mathrm{lb}$ of back tension in order to keep the wraps tight on the capstan barrels. The spooler is generally positioned approximately 10 $\mathrm{ft}$ from the low tension side of the capstan winch. This is to allow for adequate working area between the two pieces of equipment in order to connect and disconnect wire and rope mooring segments. The capstan and spooler winches are powered by a 400 volt, 3phase, $60 \mathrm{~Hz}$ electric hydraulic power pack.

Traditionally, moorings winches have been configured with single large drums. All of the mooring wire and rope shots are pre-wound for deployment and off spooled following a mooring recovery from a single drum. The Lebus winch system saves substantial ship time by not having to handle the mooring wire twice. These components can be compressed and fouled on a single drum due to high mooring tensions and are often damaged from kinking. Mooring wire and ropes that are recovered and wound onto wooden storage reels are undamaged because of the Lebus spooler winch's low hauling tensions, making it possible to redeploy these components.

The Lebus winch system requires three personnel that are thoroughly trained in the winch's operation and have a familiarity with the mooring components that are going to be deployed or hauled. These technicians are the capstan, slew and spooler operators. 
The capstan operator must have a clear understanding of the following points:

a. The double barreled capstan has a greater line pull than the spooler winch.

b. The double barreled capstan has in most cases has a hauling potential that could break the mooring wire or rope.

c. The capstan winch will hold the load only as long as there is an opposing minimum load of $125 \mathrm{lb}$ on the low tension side of the winch.

The capstan operator's responsibilities entail the following:

a. Controlling the speed and direction of haul in and pay out of the mooring wire.

b. Ensuring that the capstan winch's fair lead gates are positioned correctly.

c. Verifying that personnel are clear of the rotating capstan barrels.

The slew operator's working area is between the capstan winch and the spooling winch. This operator's responsibility is to keep constant observation of the wire or rope wraps that are bent around the capstan barrels and adjusting the axial angle of the upper capstan barrel so that the wraps are equally spaced. In addition, the slew operator's responsibilities include:

a. Monitoring the retarded tension from the spooler winch.

b. Confirming that the correct mooring components are being passed around the capstan winch.

c. Opening and closing the low tension gate.

d. During mooring pay out, ensuring that all hardware terminations are wrapped prior to passing around the capstan winch.

e. Securing a stopper line to the loose end of a deployed mooring wire during reel changes. 
The spooler operator should be efficient in reel transfer operations and be familiar with the mooring components to be used in the mooring. The spooler operator's responsibilities include the following:

a. Checking that the correct mooring wire or rope segment is on the winch.

b. That the storage reel secured to the winch has been shafted correctly, in order to prevent the reel from coming lose from the winch drive pin spinning free causing uncontrolled mooring wire slack on the capstan drums.

c. Verifying that personnel are clear of the spooler winch prior to capstan operator starting payout or hauling in.

d. Keeping the line in setting on the spooler winch high enough to provide adequate back tension on the mooring wire or rope against the capstan drums to prevent slippage.

e. The spooler operator must never shift the winch into the pay out or neutral mode while there is a load on the high tension side of the capstan winch.

\section{Precision Survey}

During the time that a mooring system falls to the seafloor when deployed, it is subject to some drift along the way due to currents and wire angle. This is especially true for anchor last deployments where the mooring system is stretched out horizontally during the operation, so that the system will typically fall around $15 \%$ of length of the mooring away from the anchor drop site. For anchor first deployments, this effect is much less since the mooring is already stretched out vertically, and the anchor has less distance to fall. The BGFE/BGOS moorings were designed for the top float to be only 50 $m$ from the surface when installed, and were deployed anchor first, so that anchor would only have to drop less than $100 \mathrm{~m}$ when let go during the deployment. Consequently, it was expected that the locations where the moorings were let go during deployment would be very close to the locations where the anchors were actually positioned.

However, for recovery operations in sea ice, it is extremely important to know the exact location of the mooring, so the system is not released under ice floes, but rather in 
open water areas. Therefore, a close range acoustic survey on transponders mounted on the mooring was performed prior to each recovery operation. Basically, the survey consists of measuring slant range response times of acoustic pulses from a transponder on the mooring from several different locations around the expected mooring site, and determining the intersection of the circles.

The survey begins by selecting a location near (typically within $1 \mathrm{~km}$ ) of the mooring site and hanging an acoustic transducer over the side of ship, between 5 to $10 \mathrm{~m}$ below the sea surface. Markings on the transducer cable may be used to facilitate determining the actual depth of the transducer, which is needed for the calculations. On the BGOS moorings, Benthos transponders are mounted on the top flotation spheres for survey purposes, but the Edgetech acoustic releases at the bottom of the mooring could also be used as transponders for the survey. Using the transducer deck unit (in our case an Edgetech model 8011), an interrogate frequency pulse is sent to the transponder, which responds with a reply frequency pulse. The time between pulses (travel time) is measured by the accurate time clock in the deck unit, and displayed (or may be recorded digitally). Simultaneously, the location of the survey point must be recorded.

Ideally, the location of the survey point is the exact location where the interrogate transducer is positioned. Here, we obtained GPS locations from the ship's bridge, so that there was some offset (on the order of 20-30 m) between the recorded and actual transducer locations. This discrepancy will result in some error in the measured travel time, and will generally reduce the precision of the triangulated mooring location.

An acoustic survey software program developed at WHOI by Arthur Newhall is used to perform the calculations for determining the actual mooring location using a least squares estimation algorithm on the intersection of the data from the survey points. In addition to the survey point response times, the program requires entries for the depth of the shipboard transducer, depth of the mooring transponder and speed of sound of the seawater; sound speed profiles were obtained from a CTD cast. On the BGOS moorings, the transponders were between 50 and $80 \mathrm{~m}$ deep, and the mean speed of sound in the upper layer was approximately $1460 \mathrm{~m} / \mathrm{s}$. 
Using the travel times (which are slant times between the transducer and the transponder), depths, and speed of sound, the slant times are converted into horizontal ranges which are plotted as circles around the respective survey locations. The least squares estimate of the intersection determines the actual mooring location. The estimates used for the speed of sound and transponder depths can be adjusted to improve the intersection of the circles. Sometimes survey locations too close to the mooring site can produce erroneous circles, probably because the return time is too quick for the deck unit so that it detects reflections.

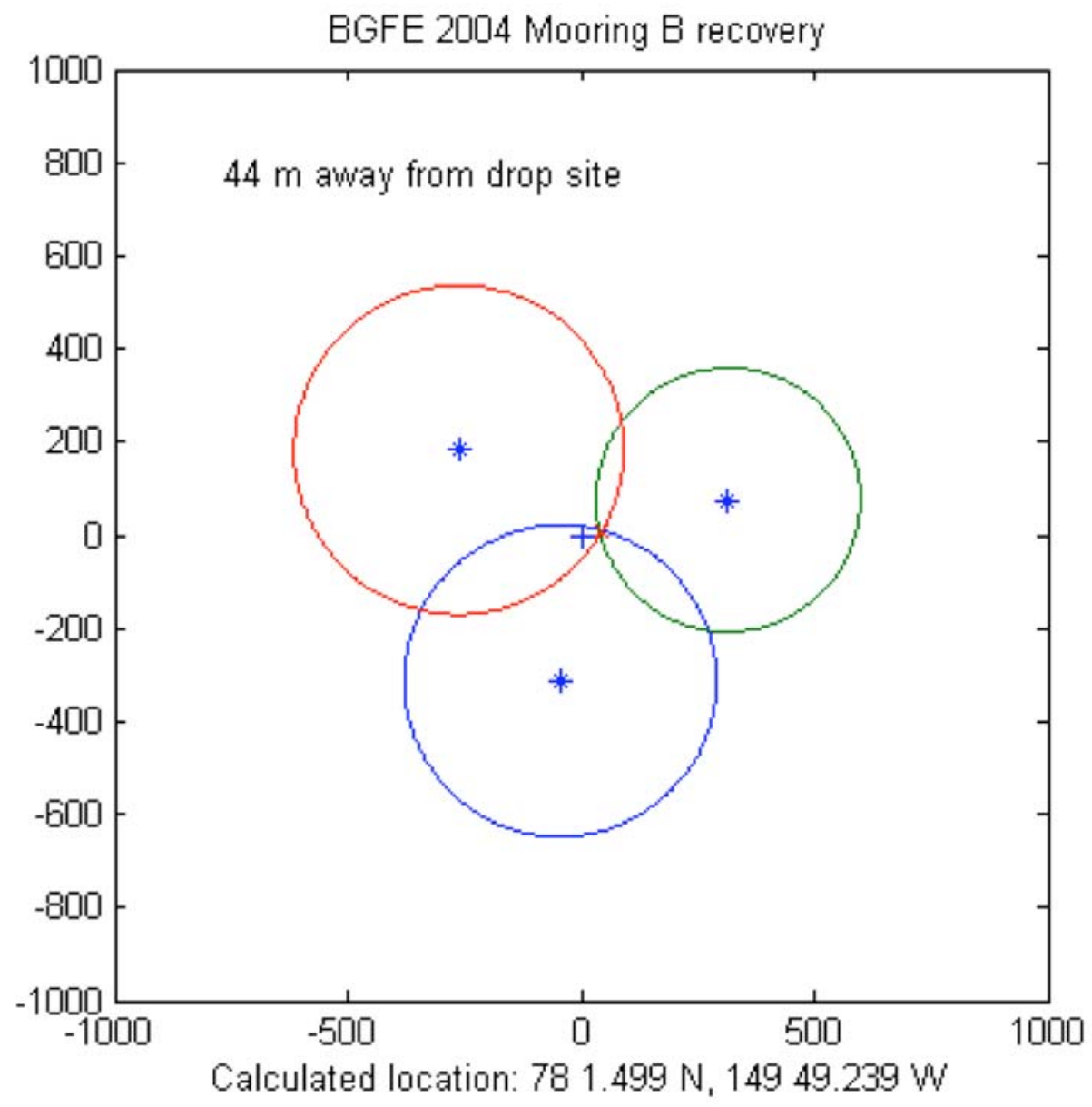

Figure 4. Survey plot for mooring B. 
Uncertainties associated with the location, speed of sound, and transponder depths added up to an apparent error of approximately $20 \mathrm{~m}$ in the range of any single survey

point. However, by taking multiple survey points, the statistical error of the triangulated estimate is reduced. The error in the location was the largest contributing factor, and could be reduced by obtaining location directly over the shipboard transducer using a hand-held GPS.

During the 2004 field operations, a full survey was not conducted at mooring A but a single range was taken $100 \mathrm{~m}$ from the mooring which coincided with the expected location. The survey from mooring B (Figure 4) indicated the actual mooring site was 44 $\mathrm{m}$ away from the expected location. For some unexplained reason, the survey from mooring $\mathrm{C}$ indicated that the actual mooring site was $183 \mathrm{~m}$ due west from the mooring site.

\section{Maneuvering and Positioning of Vessel Prior to Release}

After determining the exact location (latitude and longitude) of the mooring from the acoustic survey, the ship traveled to the site and was positioned directly overhead. A visual examination was then performed to establish both the thickness of ice in the area, and if there were any leads (lanes of open water) present. Set and drift calculations were then performed to see how natural forces (wind and current) affected the vessel's positioning over time. This is very important in determining the ship's overall movement in relation to the mooring's position.

The ice concentration on the site then determined the next course of action. At every site, the ice concentration (from analysis by Environment Canada) was 9/10ths or greater. Looking at RADARSAT satellite imagery and by visual inspection, the ice observer on board determined whether the ice was first year, second year, or multi-year and estimated the total mass at the different sites. If necessary, the ship would spend up to 2-3 hours breaking up the ice, attempting to create an open pond sufficient for the top sphere (buoy) of the mooring to surface when released. 
During all three mooring recoveries the use of the ship's "Wartsila Bubbler System" was essential to keep the ice clear from starboard (where the A-frame used for hauling the moorings was located) and for positioning the ship without having to use excessive engine and thruster power. Typically used for reducing ice friction during ice breaking, the bubbler system consists of two large air compressors capable of outputting air at $6 \mathrm{~m}^{3} \mathrm{~s}^{-1}$ at $190 \mathrm{kPa}$ through various vents located along the forward and lateral waterline on both the port and starboard sides. At any given time, the operator can activate different groups of vents in order to focus the bubblers on specific areas. The use of the bubblers was very important to the success of the mooring operations, especially in the heaviest ice conditions.

At mooring site A, the ice was mostly first year, and there were many leads and a few open water ponds. As it was the first site that we visited on the cruise, it was the first opportunity to put the tactics described above to use. After several hours of breaking the ice, it was found that, because of the leads present, the ice would spread out to create open water. Once it was concluded that a large enough pond was present (for at least 3 minutes), the decision to release the mooring was made. The position of the mooring at the time of release was directly underneath the vessel. It took approximately 30-40 seconds for the buoy to surface. By the time the buoy surfaced, the ship had moved far enough for the buoy to surface off of the starboard by about 20-30 meters.

The differences found at site B were: the ice was both first year and second-year, there were fewer leads, and there were fewer ponds visible. This changed the tactics slightly. The captain decided to spend more time with the survey, breaking up the ice, and determining set and drift, to make sure that it was possible to create a patch of open water. Because there were less leads present, it took more preparation time leading up to the release of the mooring.

At site $\mathrm{C}$ there were no leads present, it was all multi-year ice, and there were no visible open water ponds. After many hours of breaking ice, still no leads or open water areas were created because there was more ice present, no leads, and no wind to distribute the crushed ice. An adaptation was made when the mooring was ready to be released. Instead of keeping the mooring underneath the vessel as in site A and B, it was 
decided that the mooring would be positioned at the stern. The release command was given and the Captain backed the ship hard astern to clear the ship of the surfacing buoy, and to create the open water necessary for the recovery.

The main conclusions drawn are that heavy ice concentrations can be overcome with patience and by taking the essential steps described above to create an open water area exactly where needed. Without open water, there is a risk that the buoy could get trapped underneath a larger ice flow and make it virtually impossible to recover the mooring. Under the most severe conditions, as encountered at mooring site $\mathrm{C}$, the need to position the mooring at the stern while backing the ship is critical to create an opening. Without that adaptation there simply would not be enough time or space for the mooring to surface.

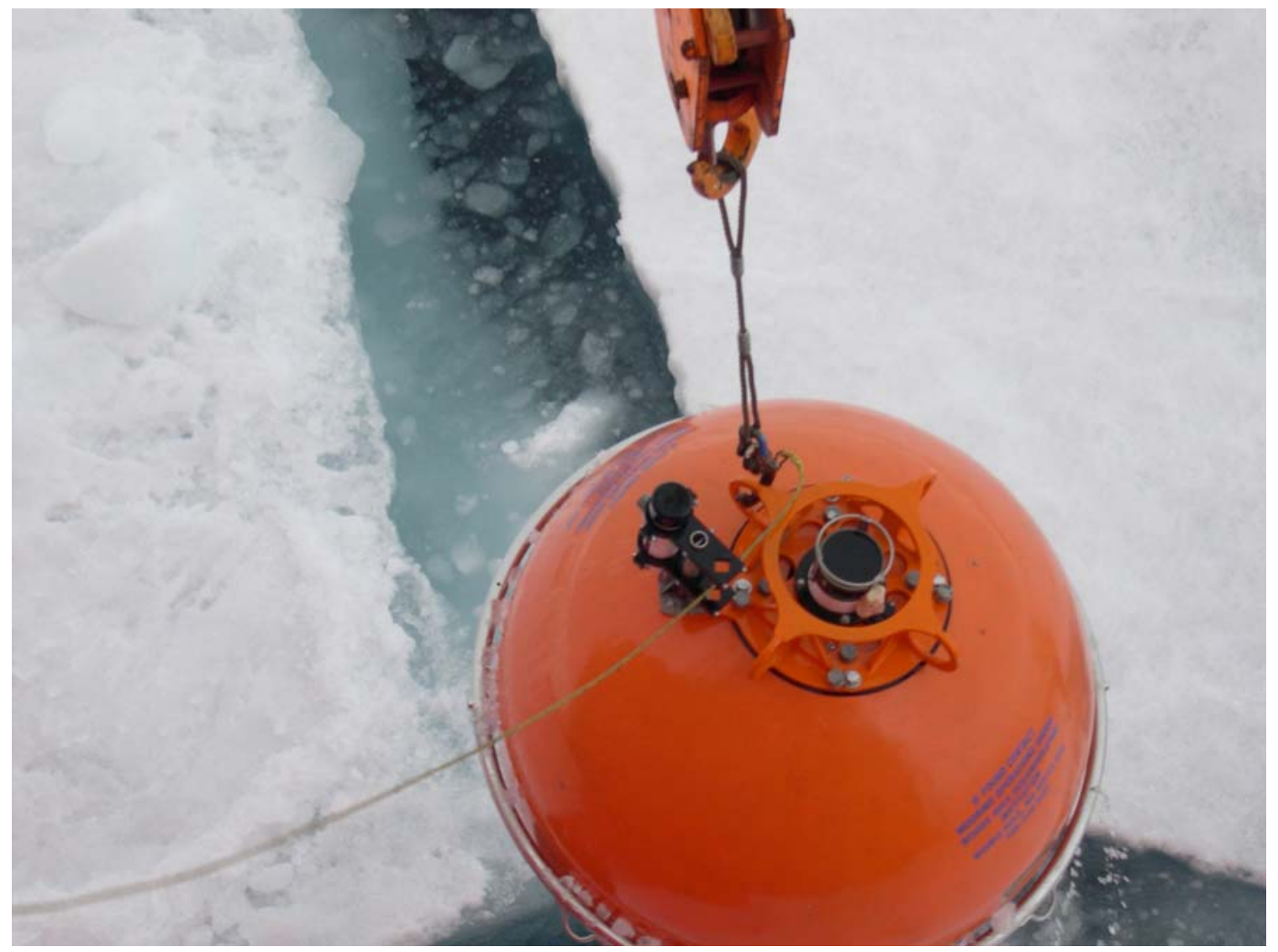

Figure 5. Top flotation sphere being recovered using the ship's crane. 


\section{Recovery Operations}

Due to the high free board of the LSL fore deck above the water $(10 \mathrm{~m})$, it would be extremely difficult to attach to surfaced mooring components with conventional pickup poles and hooks. Some traditional methods used from ships with a high freeboard for attaching a recovery line were either done using a small boat or by lowering a person in a man basket. Both methods are time consuming and labor intensive and the launching of the small boat would be dependent on the ice conditions on the day of recovery. When working in the ice there is no sea state induced motion, so at the suggestion of the Boatswain, we adopted a method using an open-end recovery hook and steering tag line.

The recovery hook was suspended on a 3-meter wire pennant from the block on the crane. Once the mooring sphere had surfaced, the Captain maneuvered the ship to a point where the sphere was directly under the position of the cranes on the fore deck. The open ended hook was lowered and skillfully positioned using the steering tag line into the pickup point on the sphere (Figure 5). Once hooked, the sphere was hoisted up out of the water. This hooking method relied on skillful coordination between the person steering the recovery hook and the crane operator but proved to be a reliable and a less time consuming method of retrieving gear out of the water in ice covered conditions.

Once hoisted out of the water, the crane maneuvered the sphere into a position directly under the A-frame. A vertical chain stopper with a safety hook attached to the bitter end (previously suspended from a pad eye on the A-frame) was then snapped into a sling link (disconnect point) under the sphere. The load was then transferred to the chain stopper, and the buoy was disconnected and craned to a position on the deck of the ship where it was secured.

The traction winch tag line was then shackled into the stopped off sling link and the winch then took the load of the mooring so the vertical chain stopper safety hook could be removed. At this point, the mooring wire was hauled up far enough for the removal of the upper MMP bumper stop. Once the bumper was removed, the winch began hauling in the first shot of $1995 \mathrm{~m}$ of 5/16" wire rope. When the termination of the first shot of wire rope reached the winch, a preassembled $1 / 2$ " chain bridle shackled to the winch base was used to secure it, and the load was transferred to a "Yale Grip" which 
was shackled to the chain bridle, thus taking all the weight away from the winch drums (Figure 6).

This allowed the winch tag line to be unshackled and the spool containing the tag line to be replaced by a collapsible wire coiler. The wire rope would not be reused on any deployments therefore the coiler allowed $~ 300$ meters of 5/16" to be bundled and stored then disposed of at WHOI. The coiler was only used on the recovery of A. On subsequent mooring recoveries, the wire was wound on the empty spools used for the previous deployment and stored on deck. When the recovery process continued, the termination was wrapped in canvas to protect the winch drums while spooling around the drums of the winch.

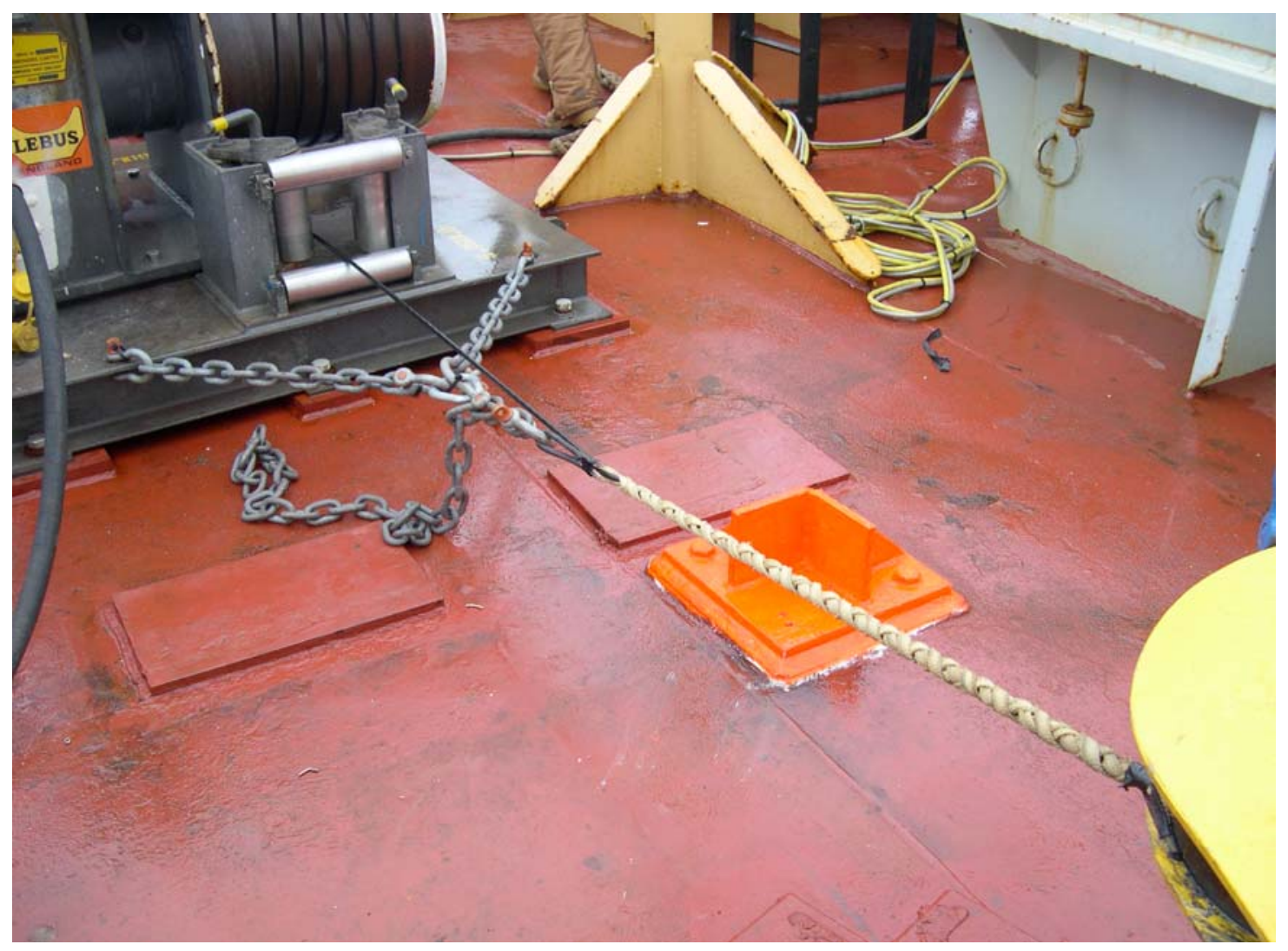

Figure 6. Wire rope section secured using a Kevlar "Yale" grip. This procedure was used to remove tension from the traction drums when changing reels on the traction winch spooler. 
At the bottom end of the $1995 \mathrm{~m}$ shot of wire rope, the MMP was retrieved resting on a second bumper stop. The MMP was hauled in until the vertical chain stopper could hook into the sling link just below the bumper stop. The winch then payed out enough wire rope to transfer the load and position the MMP and bumper stop on the deck to be disconnected. Once the MMP was safely on deck, the load was shifted back to the winch and the remaining length of the $1995 \mathrm{~m}$ shot of wire was brought in.

However, due to the backup flotation positioned at the bottom of each mooring and spring effect of the wire upon release, each mooring typically had some entanglements (wuzzles) in the wire rope which complicated the recovery. Where this occurred, the mooring had to be stopped off while portions of the wires were sorted and brought on deck (sometimes manually, at other times in bites using the vertical chain stopper, and once using the ship's windlass as a secondary winch). At times,

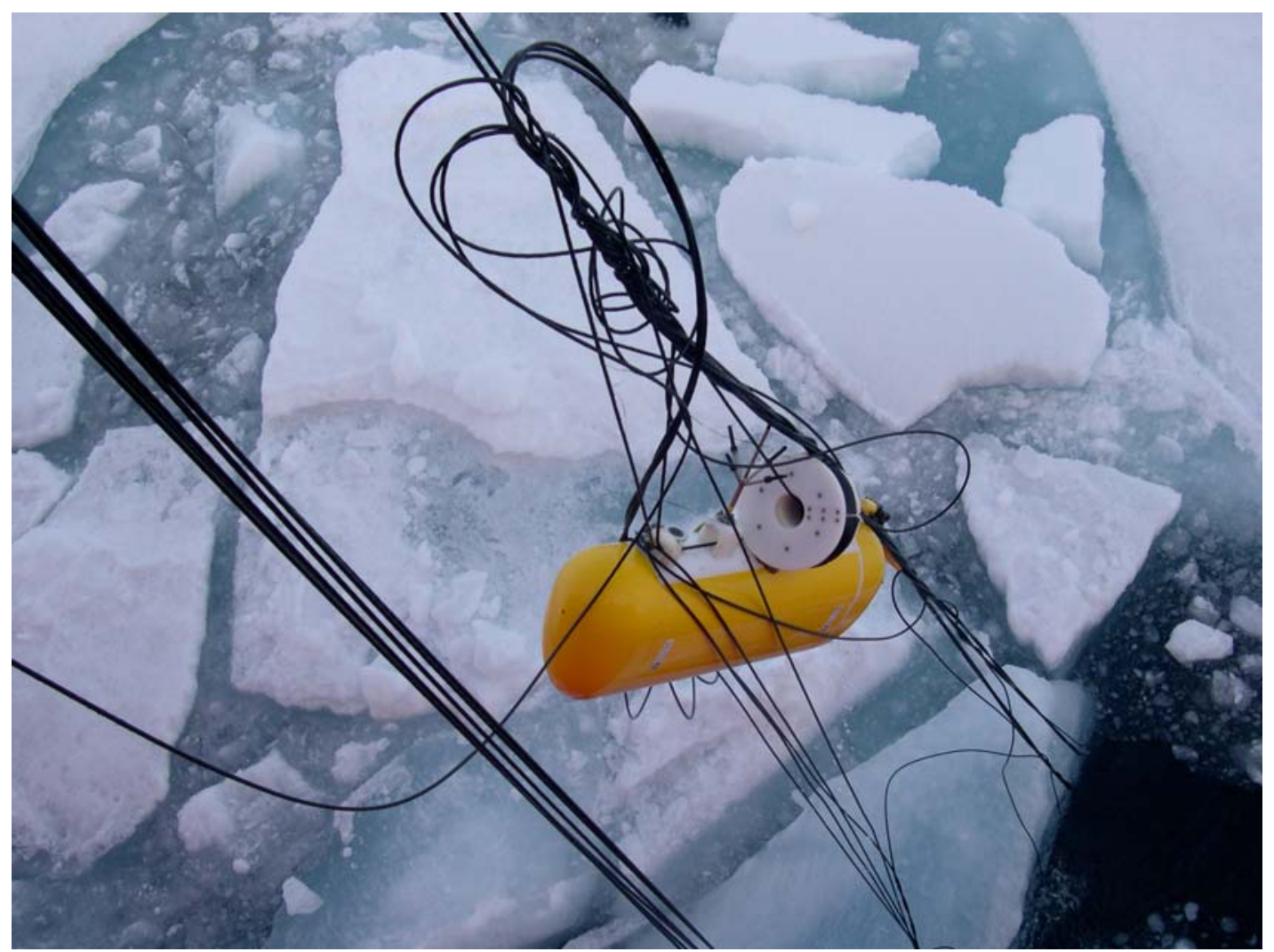

Figure 7. A particularly nasty entanglement of 9 wire rope segments during the recovery of the MMP on mooring C. Amazingly, the instrument was undamaged. 
entanglements of more than 5 different shots of wire were shackled together and wound around the winch at once, while making sure that they did not tangle while passing through each block. Once most of the wire shots above the flotation spheres at the bottom had been recovered, the next task was to recover the spheres.

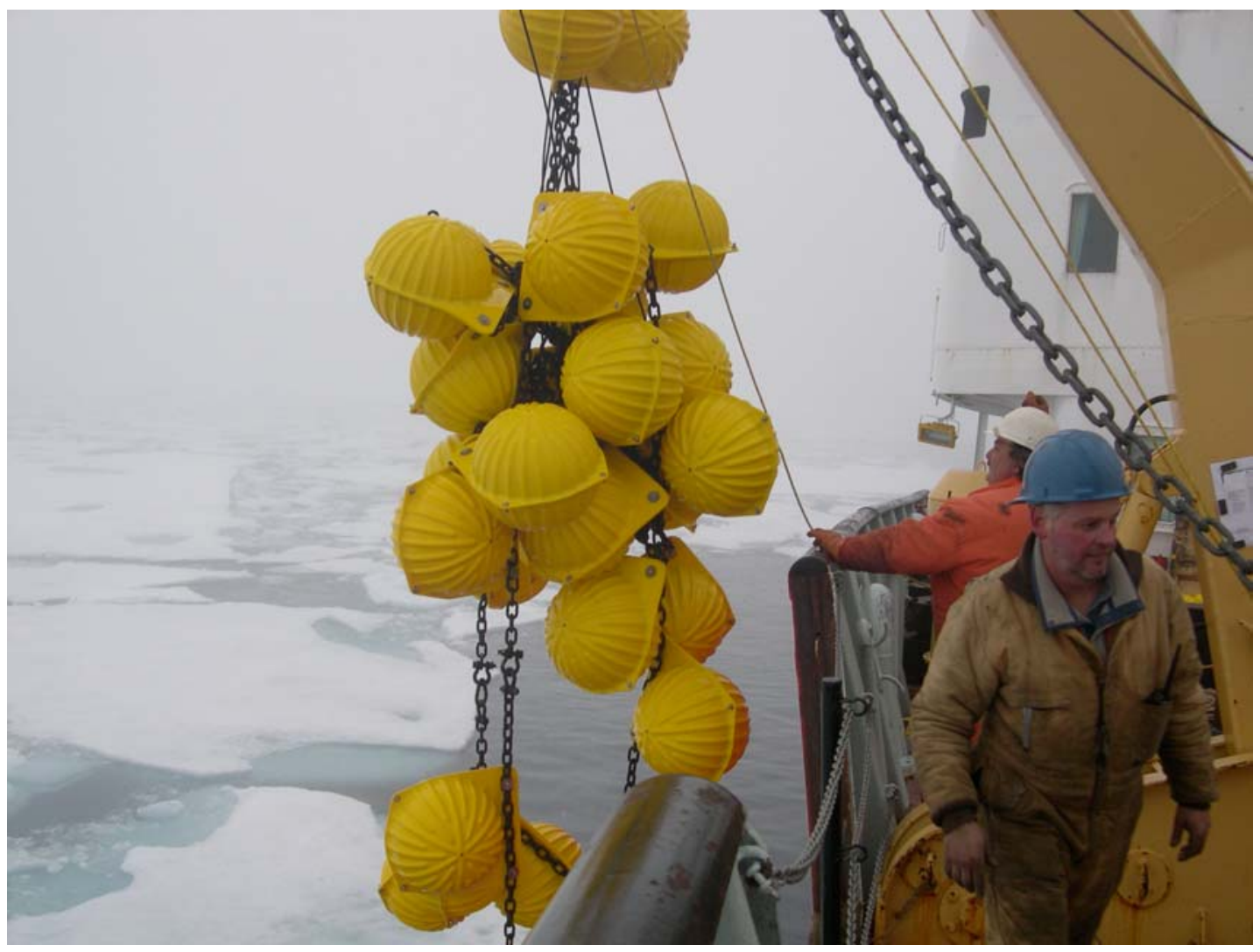

Figure 8. Cluster of glass floats comprising the backup buoyancy being recovered.

The glass spheres also snarled in large bunches (Figure 8) and sometimes were wedged just underneath the ice. In order to recover the spheres without putting too much strain on the wire, it was decided to slowly pay in the winch while the ship slowly traveled toward the direction of the wire. In other words, the captain went to the spheres instead of trying to pull the spheres to the ship. This method proved to be extremely effective and necessary in order to recover this section of the mooring safely. Because of the enormous snarls, the spheres were literally caught up in the ice and required a vertical lift instead of a horizontal drag. 
When the floats were reached, an open-end recovery hook and steering tag line was used to attach to the cluster. The ship's crane was lowered, and the Boatswain hooked onto a link of chain, a shackle, or a pear ring, then raised the cluster to the Aframe. The vertical chain stopper was used to hook into a termination of wire below the balls in order to stop off the mooring so the floats could be disconnected and brought onto the deck.

The final systems to be recovered were the dual releases and BPR (although once they were recovered before all of the backup buoyancy was retrieved due to the entanglements). The BPR was mounted on the anchor and chained to one of the releases at the bottom of the mooring. When the release command was given, the BPR was pulled from the anchor mount and ascended along with the rest of the mooring. Eventually the releases and BPR were brought to the surface away from the ice pack and secured to the vertical chain stopper. The wire was slackened, the termination was disconnected, and the load was transferred to the ship's crane. The crane then moved the releases and BPR to the deck of the ship therefore ending recovery operations.

At critical points during the recovery, especially when instruments were at the surface, the ship's bubbler system was used to clear broken ice fragments away from the starboard side.

\section{Preparations for Redeployment}

Once each mooring had been recovered, the next phase of the operation was to dump data, turn around the recovered mooring flotation packages, check releases, and prepare the instrumentation for redeployment. A full day between recovery and redeployment operations was occupied in the mooring refurbishment while the ship occupied CTD/Rosette stations.

\section{Mooring Systems:}

Even though each mooring was in an area without a significant sea state, thus reducing cyclical wear, the decision was made previously that the wire and hardware would not be reused primarily due to the tension during deployment and release during 
recovery. Therefore, complete new sets of wire and hardware were brought for each mooring.

Each mooring had a total of 52 glass floats (12 sets of 4 and 2 sets of 2 ) so there were numerous sets of hardware to change. After recovering the glass flotation balls the previous day, each set was separated and the used shackles and pear rings were discarded. Each set required complete new sets of $1 / 2$ " trawler chain (4m lengths) and 3/8" hardware (bolts, fender washers, locks, and nyloc nuts). Two technicians using a "hard hat" table setup and impact wrenches performed the process in roughly 3-4 hours.

Six releases also needed to be inspected. Ones that passed inspection and operation test on deck were turned around and redeployed. Each of these required two new anodes and a new chain bridle with two new links. However, two spare releases were utilized on the redeployment in lieu of releases with problems (one had a power problem, and another had a leaky acoustic transducer).

\section{Instrument Systems:}

Upon recovery, data was retrieved from the MMPs, ULSs, and BPRs, and the instruments were cleaned, evaluated and prepared for redeployment. Fortunately, none of the instruments were damaged, so all could be reused after maintenance. Additionally, in order to check the drift of the temperature and conductivity sensors on the MMPs, in situ calibrations were performed using a cast of the IOS SeaBird CTD/Rosette as a reference.

Data was dumped from each MMP and a preliminary analysis was performed to ensure that the instrument operated properly, and that the acquired data looked reasonable. The FSI EMCTD on the MMP was removed, configured with an independent power source, attached to the IOS CTD/Rosette frame, and configured to acquire data during a cast. This data was compared to the IOS CTD data, and if the differences were within stated accuracies, the EMCTD was remounted onto the MMP. Otherwise a spare previously calibrated EMCTD was substituted. The MMP ACMs were inspected for leakage, and if the data looked reasonable was also reused. The remainder of the MMP was refurbished for redeployment by installing a new drive roller, spring, and battery, and was reballasted for weight differences between the old and new battery 
packs (and old and new sensors, when necessary) and to reduce the difference in current drawn by the instrument between up and down casts (to enhance battery duration).

All of the ULSs and BPRs recovered in 2004 acquired complete datasets that looked reasonable. The battery pack for each ULS was replaced and since every anode was significantly they were replaced. The battery packs and antifouling devices were replaced in the BPRs.

After rescheduling (see Ostrom et al., 2004 for example), the instruments were ready for redeployment.

\section{Redeployment Operations}

Deployment operations began in the morning. In order to prevent freezing, the instruments were stored inside until just before arriving on site. While the ship calculated drift and cleared space in the ice (time varied for each mooring), the ULS and transponder were mounted to the top float and the BPR was installed on the anchor.

Each mooring was deployed anchor first using the Lebus winch. The first phase of each mooring deployment required the attachment of the dual Edgetech releases to the anchor. The ship's crane was used to both raise the releases into place over the anchor, and to lower the anchor outside of the A-Frame where the top of the $3 \mathrm{~m}$ shot of $1 / 2$ " trawler chain was secured to the vertical chain stopper (Figure 9).

The crane then hooked into the first set of glass balls that were staged on the deck and lowered them until the bottom pear ring could be shackled into the top of the trawler chain. The load was shifted to the ship's crane and the vertical chain stopper was disconnected. The load was lowered until the vertical chain stopper was connected into the pear ring at the top of the balls. The crane then connected into a second set of glass balls and the process was mimicked until all 12 sets of balls were connected onto the mooring array. In order to reduce snarling of the wire rope on future recovery operations, the glass floats were re-distributed on the redeployed mooring system so that all of the significant backup buoyancy was directly above the anchor. In other words, 12 sets of 4 were at the bottom, and 2 sets of 2 were at the top. 


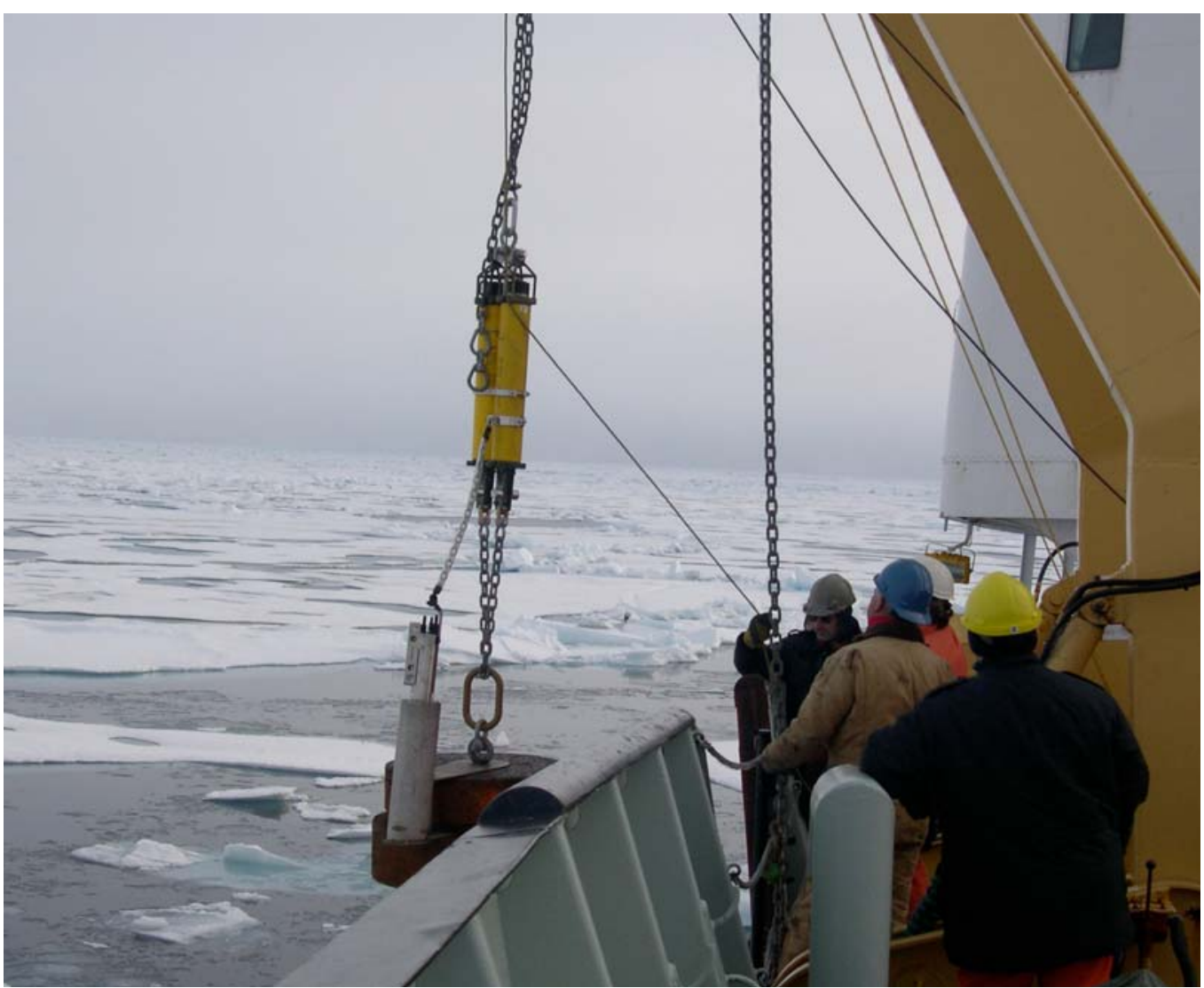

Figure 9. Lowering the anchor, BPR, and releases during anchor first mooring redeployment.

After the flotation spheres were in the water, the next four shots of 5/16" wire to be deployed were all equal to or less than $100 \mathrm{~m}$ in length. Therefore, the smaller shots of wire were pre-connected to the $500 \mathrm{~m}$ shot that was to be deployed after the smaller shots. This enabled the mooring deployment to proceed smoothly without having to stop the mooring off using the Yale-grip bridle (described above) when a small shot of wire had to be added. It is extremely important to note that six wraps of $5 / 16$ " wire were necessary around the Lebus heads in order to ensure proper tension on the wire while both recovering, and deploying the moorings. Also, before a termination went around the winch, it was wrapped in canvas for protection.

After the first shot of 500m of wire, a PARFLUX sediment trap with $0.5 \mathrm{~m}^{2}$ aperture was added to mooring A (but not B or C) at $3000 \mathrm{~m}$ depth. The same method of 
using the vertical chain stopper and the ship's crane was used in order to add this instrument.

After two more $500 \mathrm{~m}$ shots and one $10 \mathrm{~m}$ shot of wire were added to the mooring, the 1995 m shot was next. WHOI technicians and the ship's crew were all needed to add the large shot of wire. Because of hydraulic problems on the spooler, the shot had to be lifted off the deck manually with assistance from the spooler. Once in place, the wire was payed out until the bottom termination reached the vertical chain stopper where it was stopped off and the MMP could be attached. The bottom bumper stop was added, then the MMP was lifted into place and secured to the wire and carefully lifted outboard of the A-Frame. Deployment of the wire rope continued. When the termination could be visibly spotted with only several layers of wire on the reel, the mooring was stopped off using the Yale grip. The remaining wire on the reel was taken off and faked onto the deck. The winch tag line reel was moved into place on the spooler. Being careful not to knick or drag the wire, it was coiled onto the reel. The winch took the load and the Yale grip was removed. The winch was payed out until the vertical chain stopper could take the load. When the mooring was stopped off, the tag line was removed.

Once all the instruments and wire were in the water, the last piece of the mooring to be deployed was the 64" Syntactic sphere with a ULS and an acoustic transponder mounted to the top. A release hook was secured to the top bail of the sphere using a 'Lift-All' sling then attached to the ship's crane (Figure 9).

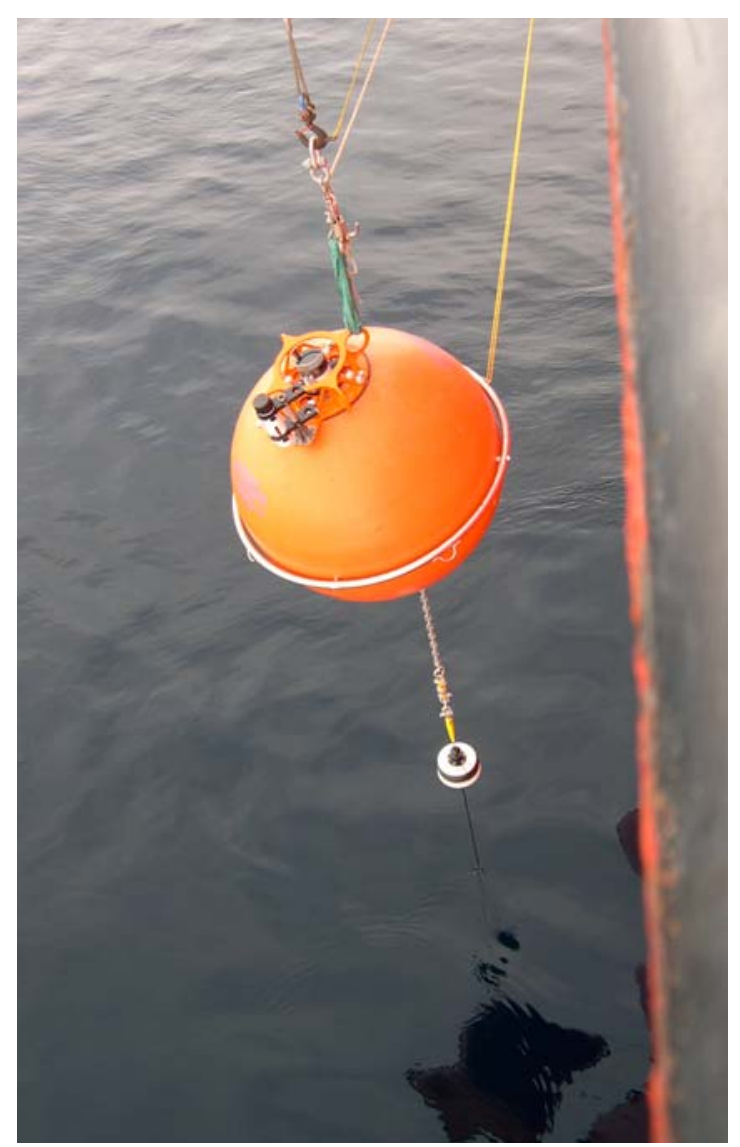

Figure 9. Top sphere deployment. 
The crane then lifted the sphere outboard of the A-Frame and the mooring was attached to the $1 \mathrm{~m}$ shot of $1 / 2$ " Trawler Chain. The crane took the load from the vertical chain stopper so it could be removed. The top sphere was held at the surface of the water, but before being released, an acoustic range was conducted on one of the releases. About a minute after releasing the top sphere, the mooring settled at the bottom, and more ranging was conducted.

The difference between ranges gave the depth of the top sphere below the surface. The release was disabled, and each redeployment mooring operation was completed in about 5-6 hours.

\section{Conclusions}

Conventional deep ocean, bottom-tethered and instrumented moorings utilizing wire-rope and glass flotation technology can be routinely deployed and recovered from icebreakers in the central Arctic ice pack.

In ice-covered regions, deployments must be conducted anchor-first. To account for the added tension and ensure a responsible safety factor, heavier wire rope and hardware must be incorporated into the mooring design. Winch and windlass (or capstan) procedures are both acceptable methods of conducting the deployment.

An accurate acoustic survey to determine the exact location of the mooring, adequate ice conditions, and skilled ship maneuvering are all essential requirements for a successful mooring recovery. Windlass (or capstan) procedures could be used for the recovery, but a traction winch is recommended. Backup buoyancy at the bottom of the mooring is advised for backup recovery should intermediate lengths of the mooring system get tangled under ice floes. 


\section{Acknowledgments}

On behalf of all of the scientists from WHOI who participated on the JWACS/BGEP cruises on the CCGS Louis S. St. Laurent in August 2003 and August 2004, we would like to extend our sincere appreciation to all the Captains, officers, and crews and to the Canadian Coast Guard organization for the successful fulfillment of the objectives of our scientific field program in both years. We recognize that the knowledge and experience of the ship's leaders was critical to the success of our field program, and would like to express our gratitude for the hard work, dedication, and professionalism that was demonstrated by all members during the cruises to the most inaccessible region of the Arctic Ocean. It has been a privilege and a pleasure working from the Canadian Coast Guard icebreaker, and we look forward to the opportunity to continue this cooperation in the future. Specifically for the 2004 expedition, we would like to thank Captain Andrew McNeill for his excellent leadership and ship handling skills, and Boatswain Blaine Blinkhorn and his deck crew for their expertise during the mooring operations.

Furthermore, we would like to thank IOS and JAMSTEC scientists for allowing us to collaborate and participate on the JWACS cruises, particularly Eddy Carmack (IOS), Fiona McLaughlin (IOS), Koji Shimada (JAMSTEC), and Motoyo Itoh (JAMSTEC). Special gratitude goes to Sarah Zimmermann (IOS) for her outstanding management as chief scientist on the 2004 expedition. Furthermore, we acknowledge the professional assistance that we obtained from Doug Sieberg (IOS) and Andrew Hamilton (IOS) during the field operations.

The BGFE project was funded by the NSF Office of Polar Programs ARCSS Program grant number OPP-0230184, including support for the first year of the field program (including deployment and recovery of the moorings). Any opinions, findings, and conclusions or recommendations expressed in this material are those of the authors and do not necessarily reflect the views of the National Science Foundation. Support to redeploy and recover the moorings for a second year was provided by the WHOI Ocean and Climate Change Institute. 


\section{References}

Aagaard, K., C. Darnell, and F. Karig, 1978. Measurements with moored instruments in ice-covered waters, Deep-Sea Research, Vol. 25, pp. 127-128.

Ostrom, W., Kemp, J., Krishfield, R., and A. Proshutinsky, 2004. Beaufort Gyre

Freshwater Experiment: Deployment Operations and Technology in 2003 WHOI Technical Report WHOI-2004-1. 